\title{
EL MANIQUÍ Y SU RELACIÓN CON EL CUERPO ENVEJECIDO ${ }^{1}$
}

\author{
THE MANNEQUIN AND ITS RELATIONSHIP WITH THE AGED BODY
}

O MANEQUIM E SUA RELAÇÃO COM O CORPO ENVELHECIDO

Sandra Leal Larrarte ${ }^{2}$ Lilia Inés López Cardozo ${ }^{3}$ Paola Rodríguez Cañas ${ }^{4}$

\section{Resumen}

El artículo hace parte de la investigación titulada "Semiótica del cuerpo: el maniquí como capital corporal en las ciudades de Armenia (Colombia), Ciudad Juárez (México), San Cristóbal (Venezuela) y Perugia (Italia)”, terminada en 2015. Las representaciones que se hacen alrededor del cuerpo, como las del maniquí, son construcciones colectivas que permiten realizar un acercamiento a la manera en que la ciudad y su gente organiza el comercio alrededor de aquel (Silva, 2006). Esto lleva a pensar la manera en que los comerciantes y vitrinistas crean mundos posibles, concebidos como una construcción cultural que genera propuestas de utopía o distopía sobre acciones del mundo contextual (Eco, 1987). En este caso, sobre la estética corporal dirigida a las masas consumistas y la manera como los ciudadanos pertenecientes a un colectivo afirman o seleccionan los estigmas sociales (Goffman, 2006) que generan la inclusión o exclusión de grupos sociales, específicamente la comunidad de personas mayores. Reconocer cuál es el mensaje que comunican los maniquís permitió crear la propuesta de lectura académica de un texto social compuesto por vitrinas y escenificaciones de lo deseado y su relación con los procesos de envejecimiento y la vejez. El maniquí jamás envejece; su cuerpo, de "piel lisa”, así lo indica.

Palabras clave: maniquís; exclusión; vejez; vitrinas; ciudad; cuerpo

\section{Abstract}

The article is part of the research completed in 2015, called: "Semiotics of the body: The mannequin as corporal capital in the cities of Armenia (Colombia), Ciudad Juárez (Mexico), San Cristóbal (Venezuela) and Perugia (Italy)". The representations that are made around the body, such as those of the mannequin, are collective constructions that allow an approach to the way in which the city and its people organize trade around the body (Silva, 2006). This leads us to think about the way in which merchants and window dressers create possible worlds, conceived as a cultural construction that generates proposals of utopia or dystopia on actions of the contextual world (Eco, 1987). In this case, on the corporal aesthetics directed to the consumer masses and the way in which citizens affirm or select social stigmas (Goffman, 2006) that generate the inclusion or exclusion of social groups. Recognizing the message that mannequins communicate was crucial to create an academic reading proposal of a social text composed by showcases and stagings of the desired and its relation with the processes of aging and old age. The mannequin never ages: its body of "smooth skin" shows that.

Keywords: mannequins; exclusión; old age; showcases; city; body

1 Este artículo pertenece a la investigación que se inició en la segunda mitad del 2014 y finalizó en diciembre de 2015, titulada: Semiótica del cuerpo: el maniquí como capital corporal en las ciudades de Armenia (Colombia), San Cristóbal (Venezuela), Ciudad Juárez (México) y Perugia (Italia). Avalada por la Universidad del Quindío, e inscrita dentro del grupo de investigación Semióticas de Ficción.

2 Docente de planta de la Universidad del Quindío, Mágister en Ciencias de la Comunicación. Correo: sanarida70@gmail.com. Orcid: https://orcid.org/0000-0003-1526-7413

3 Docente de planta, directora del programa de gerontología de la Universidad del Quindío. Mágister en Educación. Correo: liliai@uniquindio.edu.co. Orcid: https://orcid.org/0000-0002-6546-4661

4 Docente de cátedra en la Universidad Minuto de Dios. Exdocente de cátedra en el programa de Comunicación social - Periodismo de la Universidad del Quindío. Especialista en televisión. Correo: profesoratelevision@hotmail.com. Orcid: 0000-0001-7921-4674 


\section{Resumo}

O artigo faz parte da pesquisa "Semiótica do corpo: o manequim como capital do corpo nas cidades da Armênia (Colômbia), Ciudad Juárez (México), San Cristóbal (Venezuela) e Perugia (Itália)”, concluída em 2015. Representações que são feitas ao redor do corpo, como as do manequim, são construções coletivas que permitem uma abordagem da maneira pela qual a cidade e seu povo organizam o comércio ao seu redor (Silva, 2006). Isso nos leva a pensar sobre como os comerciantes e vitrines criam mundos possíveis, concebidos como uma construção cultural que gera propostas de utopia ou distopia sobre ações no mundo contextual (Eco, 1987). Nesse caso, relacionado com a estética corporal direcionada às massas consumistas e a maneira como os cidadãos pertencentes a um grupo afirmam ou selecionam estigmas sociais (Goffman, 2006) que geram a inclusão ou exclusão de grupos sociais, especificamente a comunidade de pessoas maiores. 0 reconhecimento da mensagem que os manequins estão comunicando permitiu a criação de uma proposta de leitura acadêmica para um texto social composto por vitrines e encenações do que se deseja e sua relação com os processos de envelhecimento e velhice. 0 manequim nunca envelhece; seu corpo, de "pele lisa", indica isso.

Palavras-chave: manequins; exclusão; velhice; vitrines; cidade; corpo

Fecha de recepción: 15 de febrero de 2019

Fecha de evaluación: 08 de marzo de 2019

Para citar este artículo:

Leal Larrarte, S., López Cardozo, L., Rodríguez Cañas, P. (2019). El maniquí y su relación con el cuerpo envejecido. Lúdica Pedagógica, 29, 69-80. https://doi.org/10.17227/ludica.num29-11084 


\section{INTRODUCCIÓN}

Si se atiende a la idea de que la sociedad está obsesionada por la apariencia, se debe reconocer que el maniquí forma parte del capital corporal (Bourdieu, 1986) y de la expresión semiótica (Finol, 2008). Como bien lo afirma Le Breton (2002), el cuerpo es un significante, de género, de edad, de gustos, por lo que estos muñecos expresan, desde las vitrinas comerciales, el representamen corporal establecido, no solo por la época, sino por el lugar.

En la sociedad posmoderna (Jameson, 1991), ávida consumidora de imágenes, el cuerpo pasa de ser un emblema individual a ser pastiche, es decir, a ser imitación de algo, pero sin un trasfondo que lo defina. Se entiende que el maniquí se ha convertido en un objeto cultural que imita al ser humano y viceversa, pero lo fragmenta y, con ello, lo restringe. El estudio, de tipo exploratorio-descriptivo, permitió interrelacionar las categorías, al observar la puesta en escena de los maniquís en las vitrinas, así como la actitud de quiénes los observan. El ejercicio llevó a reconocer que los maniquís, a pesar de ser figuras estandarizadas, pertenecen a imágenes culturales que se desarrollan y se apropian según la cultura en la que se exhiban. También se pudo observar que imitan el proceso de envejecimiento humano, pero solo hasta un punto. De ahí surgió la pregunta que orienta este artículo: ¿cuál es la representación del proceso de envejecimiento que se da en el espacio comercial de las vitrinas?

\section{EL CUERPO COMO FORMA DE EXCLUSIÓN/INCLUSIÓN}

Son numerosas las investigaciones realizadas en relación con el cuerpo humano, desde diferentes disciplinas: sociología, psicología, antropología, gerontología, semiótica, publicidad, educación física, en otras. Sin embargo, en los últimos años se ha incrementado la visualización del cuerpo desde su nivel estético, como imagen y figura de perfección humana. En efecto, Infantino (2010), en su artículo "Prácticas, representaciones y discursos de corporalidad. La ambigüedad de los cuerpos circenses", manifiesta que no fue sino hasta la década de los setenta que la denominada "antropología del cuerpo" comenzó a delinearse como un campo de estudio específico.
Diversas investigaciones indagan sobre las formas en que cada sociedad, en sus diferentes etapas, modela el cuerpo y sus representaciones. De eso se desprende que, si bien la presencia del cuerpo es constante, no lo es su manera de entenderse.

Así, el cuerpo, entre múltiples miradas, significados y sentidos de vida, encuentra sus propias interpretaciones: un simple instrumento de placer, símbolo de perfección, o un elemento de tortura. En la sociedad moderna, el cuerpo entra a formar parte de la sociedad de consumo, a través de las diferentes prácticas que lo moldean, como el ejercicio físico, la moda y los tatuajes. Pero es especialmente la publicidad la que genera un estado de subordinación del cuerpo a unos esquemas estéticos inalcanzables. Es en este punto donde la mujer alcanza su cenit como objeto-símbolo: su cuerpo es configurado como imagen para los hombres y espejo de las demás mujeres (Amoros e Irigaray, citados por Bernal, 2014).

A través del tiempo, el cuerpo ha generado un sinnúmero de estereotipos, que van desde los diversos conceptos de belleza hasta los de fealdad, reflejados estos en un cuerpo supuestamente imperfecto. Hoy en día, el cuerpo se mide, se pesa y se cuantifica en años; existen parámetros de medidas para los distintos contornos del cuerpo; de gramos, para identificar la cantidad de grasa permitida socialmente; y de años, para encasillar a las personas en la denominada "belleza estética aceptable". Así, aparecen términos que definen la belleza: "cuerpo de reina", "cuerpo de Barbie", "cuerpo curvy" (cuerpo con aparente sobrepeso, pero con forma de reloj de arena).

Conforme surgen los estereotipos de lo bello, por descarte aparecen los estereotipos de lo feo, y dentro de estos encaja la imagen de la silueta encorvada y la piel arrugada, como denotación del cuerpo envejecido. En respuesta, una imagen que se niega a envejecer circula en los medios. Se trata de una idea de juventud eterna que desconoce y rechaza el ciclo vital. Lo natural pasa a ser mito, y el estatismo del cuerpo en el tiempo se ensalza.

Lo anterior explica por qué se puede hablar de capital corporal. Por capital entendemos

[...] una forma - digamos - de energía, de fluir que adquiere básicamente tres aspectos: es circulante en tanto se transforma y muta, es fijo en tanto 
se objetiva en bienes y es líquido en el sentido de constituir la resultante en la relación entre lo que se incorpora, producto de la acumulación, y los costos de esa acumulación de algún tipo de patrimonio (Bowles, citado por Uro, 2006, p. 843).

El cuerpo como capital es esa energía cultural que circula entre la sociedad, a través de formas concretas de mostrarse: su forma de vestir, de maquillarse, de adornarse según su condición de género o situación socioeconómica. Todos estos elementos son lenguajes que se yuxtaponen para formar el texto "cuerpo", dentro de la organización simbólica humana, como sello de garantía social y moral del capital social.

\section{SEMIÓTICA DEL CUERPO}

Se debe reconocer que todo en lo que interviene el ser humano comunica. Por tanto, su cuerpo mismo, sus gestos, sus actitudes, el vestuario, los accesorios, su forma, todo en él está al servicio de la interpretación del otro. Para autores como Turner (2004), el cuerpo es el elemento más ubicuo y el código más obvio como fuente de categorías sociales, pero la cuestión principal está en que resulta más importante estudiar los efectos del poder sobre el cuerpo, pues este es el que abre las puertas a las lecturas que se hacen de aquel.

Dentro de los estudios sobre el cuerpo, un tema que poco se aborda es el de la educación. El cuerpo es símbolo, pero es un símbolo que no está finalizado (Gehlen, citado por Turner, 2004). Según Planella (2005), debe ser educado, ya que ha dejado de ser un elemento de la biología para ser un elemento de transformación y personalización. Planella propone que no solo se debe hacer pedagogía para la adolescencia, en relación con la aceptación del cuerpo, sino también para el envejecimiento, para entender el proceso y vivirlo a plenitud.

El cuerpo, como elemento social, es moldeado por la cultura desde un "deber ser", así como por los conceptos estéticos que rigen el contexto y lo llevan a la representación. En sí mismo, cualquier individuo es un sujeto que representa su "deber ser" frente a su entorno, una imagen estereotipada que representa a otros de su misma clase. El cuerpo individualiza al sujeto, pero a la vez lo conecta con su medio social.
Según Turner (2004), los cambios creados por el movimiento feminista, la posmodernidad en las artes, el envejecimiento social y la cultura del consumo han dado un giro a las teorías sociales centradas en el cuerpo.

De acuerdo con Finol (2008, p. 384), estudiar el cuerpo desde la semiótica es verlo desde

[...] el fenómeno estético corporal como parte de una cultura y de una sociedad, pero también como el resultado de una compleja serie de operaciones semióticas que privilegian el cuerpo como mensaje, como espectáculo, como sentido; un sentido que, a su vez, marca la sociedad y la cultura a las cuales activamente se articula.

Lo anterior equivale a decir que estudiar el cuerpo como fenómeno de la comunicación es también estudiar sus formas de representación, vistas desde los contextos socioculturales con que se vincula. Siendo así, el cuerpo se puede estudiar desde cuatro perspectivas:

- Cuerpo-lenguaje. En este caso, se habla del cuerpo como expresión denotada, es decir, como un signo completo dispuesto a ser descrito como cuerpo. El movimiento y las poses que este expresa son la manera en que se vincula con las dimensiones de tiempo-espacio (kinésica). Es un lenguaje con su propia gramática y su propia historia.

- Cuerpo-objeto. Hace referencia a las maneras en que las culturas representan el cuerpo. Así, "los significantes utilizados derivan de aquellos sistemas de signos - lingüísticos, gestuales, icónicos- que sirven para representar o describir al cuerpo como un objeto semiótico, entendido en el sentido que a estos dos últimos términos les da la semiótica peirceana" (Finol, 2009, p. 386).

- Cuerpo-referencia. Es el estudio del cuerpo como soporte de otros signos: la forma y los tipos de los tatuajes que una persona lleva, el tipo de peinado, etcétera, son, entre otros signos, los que esta perspectiva se encargaría de estudiar. Implica reconocer el cuerpo como elemento que presta su significado, a la vez que es reconstruido por las semiosis 
procedentes de los otros signos. Esta relación crea unas reglas de inclusión o exclusión, dependiendo del contexto social encargado de leerlas, así como de producirlas.

- Cuerpo-espacio. Son objetos signo, modelados a partir del cuerpo o en función de este, sin cuya presencia serían ininteligibles. Son funcionales en cuanto poseen un volumen, ocupan un espacio, manejan una expresión estética y tienen un servicio.

Estas cuatro perspectivas de estudio descansan sobre la cotidianidad humana, demuestran que el cuerpo es parte del hábito de la vida y de la gramática de las relaciones humanas. El cuerpo - y sus representaciones - siempre está orientado hacia las lecturas que lo dimensionan dentro de lo bello, lo grotesco, lo estético y toda la infinidad de interpretaciones emocionales y subjetivas que derivan del contexto social e histórico en que se desenvuelve.

\section{MUNDOS POSIBLES Y VITRINAS}

Los mundos posibles, tal y como lo afirma Umberto Eco en su libro Lector in fabula (1987), se construyen con el cruce de tres mundos que son importantes a la hora de interpretarlos: el mundo real de referencia o Wo, el mundo posible que afirma el autor o Wn y el mundo posible que imagina el lector o $\mathrm{Wr}$, los cuales están presentes en todas y cada una de las obras o acciones imaginadas (en general, en el mundo de las ideas), y son inseparables. Eco reconoce que el mundo "real" de referencia es una construcción cultural que se debe de tomar en cuenta a la hora de elaborar las interpretaciones del receptor, puesto que son una importante mediación cultural que inclina la balanza hacia las posibles interpretaciones. Con esto en mente, se entiende que para cada realidad en que se desenvuelve el receptor habrá una lectura de ese mundo posible al que se refiere el autor, que para el caso de este estudio serían los diseñadores, tanto de maniquís como de vitrinas.

La mercancía exhibida en los almacenes constituye parte del merchandising visual más naturalizado durante el último siglo. El comercio aprovechó la tendencia natural de los seres humanos al voyerismo, $\mathrm{y}$, desde que aparecieron los almacenes de moda en la París del siglo xIX, el voyerismo ciudadano es una forma de recreación fácil y barata, que ya forma parte de la cultura que se ha desarrollado alrededor de las vitrinas. Ellas mismas son un mensaje y una forma de comunicación, tienen una naturaleza simbólica que se adapta en función de la realidad circundante (Cedeño, Centeno y D’aubeterre, 2015).

El maniquí de moda no está hecho solo para que se cuelgue ropa sobre él, sino para crear sueños y estéticas, para permitir que cada persona piense su mundo posible desde el punto de vista corporal. Los maniquís se diseñan teniendo en cuenta esto, añadiendo el factor de los gustos de las comunidades en las cuales se va a exhibir, así como la calidad y el posicionamiento social de la mercancía que se quiere vender.

\section{MANIQUIIS E INDUSTRIA CULTURAL}

Desde que autores como Horkeimen y Mattelart (1988); y Mattelart y Piemme (1982), entre otros, empezaron a hablar de industria cultural, la principal preocupación siempre fue el criterio de autenticidad frente a las dinámicas de reproductibilidad. Como lo afirman Szpilbarg y Saferstein (2014), la autenticidad en el arte proviene de la idea de algo que puede ser achacado a un autor y que posee un valor casi místico, que va más allá de su valor mercantil. Pero, ¿qué pasa cuando ese "algo" se pensó desde el inicio para ser una copia?

En el caso del maniquí, la identidad "mística" procede de su original, es decir, del cuerpo humano. Darle forma y aspecto humano a un maniquí, más que una labor de fabricación, es todo un proceso artístico, donde se pone a prueba la capacidad humana de replicarse a sí mismo a imagen y semejanza.

La mayoría de la población tiende a valorar la figura que se aproxima al cuerpo que goza de valor comercial. La propensión a sobrerracionalizar el mundo se enfrenta a su némesis con estos muñecos antropomorfizados, tan parecidos a las personas que son capaces de hacer saltar sus mecanismos de defensa y reconocerlos como el espejo en el que cualquier persona se ve cada vez que se mira al probarse una prenda de vestir o sale a la calle.

La moda, una industria para la cual fueron creados los maniquís, es una manifestación de esa complejidad 
que es el concepto de cuerpo como capital social. La globalización de la economía y la influencia del mercado hacen posible la homogeneización de los estilos de vida, los referentes para relacionarse con la sociedad y consigo mismo y, en consecuencia, las representaciones del cuerpo.

Las diferencias económicas, de sexo, de edad y de escolaridad, fundamentales en la determinación de los intereses y valores de los grupos humanos, parecen funcionar poco a la hora de resumir los ideales corporales.

En todo caso, bajo el actual marco de valorización de las actividades relacionadas con el cuerpo, los medios de comunicación están orientando la conducta corporal hacia un estilo de vida saludable, afirmado en la corporalidad que proyecta la publicidad, pero ignorando totalmente los cambios biológicos producidos con la edad o los diferentes cuerpos que pueden existir.

\section{CUERPO Y VEJEZ}

Goffman (2006), en su estudio sobre el estigma, afirma que este es una relación entre atributo y estereotipo, donde el individuo estigmatizado supone una calidad de diferente. Cualquier persona, como parte de un grupo social culturalizado, es a veces incapaz de darse cuenta de esta estigmatización a la que se somete o es sometido, y cuando reconoce el estigma, difícilmente posee las herramientas para evitarlo. Con esto en mente, en el conjunto de creencias actuales, al cuerpo se le exigen atributos de belleza y juventud difíciles de alcanzar fuera del mundo casi irreal de los medios.

Los medios masivos de comunicación magnifican el ideal del cuerpo femenino perfecto, joven, y el maniquí es una de sus representaciones. No envejece, no se permite envejecer y no puede envejecer; no sube de peso y está siempre a la moda.

Al explorar la web, en busca de un maniquí que represente a los adultos mayores, llama la atención lo escasas que son las imágenes frente a la realidad demográfica. Se encontró un solo maniquí para la venta con aspecto de persona mayor. Este maniquí se vende como producto para la formación en una línea de salud, bajo el título "Maniquí simulador para el cuidado del paciente geriátrico". Se trata de un muñeco de aspecto femenino, en el cual se manifiesta un leve intento de líneas de expresión en su rostro para semejar una persona mayor.

El sociólogo Pierre Bourdieu (citado por Mernissi, 2006) sugiere que se activan códigos ocultos en capas más profundas de lo que se aparenta en una industria como la de la moda. Las personas renuncian a la evolución natural que produce el envejecimiento y a las consecuencias relacionadas como un cuerpo que engorda.

Las imágenes creadas en las vitrinas a través de los maniquís organizan el entramado de un nuevo mapa cultural que muestra aquello en lo que la sociedad está pensando y la forma como se piensa a sí misma. Recrean expectativas sociales que permiten, transmiten y apoyan la transformación cultural.

\section{METODOLOGÍA APLICADA}

El ejercicio se realizó a través de una investigación exploratoria descriptiva, que permitió generar un entramado entre las referencias teóricas y epistemológicas, para describir el fenómeno estudiado en una realidad concreta.

La unidad de análisis estuvo conformada por fotografías de maniquís (aproximadamente 1200), recogidas en cuatro ciudades de cuatro países: Ciudad Juárez (México), Armenia (Colombia), San Cristóbal (Venezuela) y Perugia (Italia). El criterio de inclusión fue la variedad de sus maniquís y las similitudes en la representación del cuerpo.

Para definir cuáles fotografías debían exponerse en la investigación, y cuáles las publicaciones derivadas de esta, se eligieron las que representaban más claramente las diferenciaciones que se crean según el entorno cultural y la manera en que se manifiesta el proceso de envejecimiento. Al final, se escogieron ocho, con el fin de sustentar visualmente la constante negación del cuerpo envejecido y los límites de edad que el comercio ha trazado para definir las normas estéticas en el cuerpo.

La técnica de recolección de la información utilizada fue la observación de los maniquís en las vitrinas y los registros fotográficos. Posteriormente, fue el análisis de contenido (AC), entendido como "el conjunto de los métodos y técnicas de investigación destinados a facilitar la descripción sistemática de los 
componentes semánticos y formales de todo tipo de mensaje, y la formulación de inferencias válidas acerca de los datos reunidos" (Colle, 2011, p. 8), aspecto vital para la interpretación de los datos recogidos.

El formato de observación aplicado fue el siguiente:

Tabla 1. Formato de observación

\begin{tabular}{|l|l|l|l|c|l|l|}
\hline Vitrina no. & $\begin{array}{c}\text { Lugar y fecha } \\
\text { de observación }\end{array}$ & $\begin{array}{c}\text { No. de maniquís } \\
\text { exhibidos }\end{array}$ & Pose & $\begin{array}{c}\text { Detalles significantes } \\
\text { (Mantenimiento, } \\
\text { accesorios, colores, } \\
\text { forma, raza, sexo, etc.) }\end{array}$ & $\begin{array}{c}\text { Edad } \\
\text { representada }\end{array}$ & $\begin{array}{c}\text { Mundo posible } \\
\text { representado }\end{array}$ \\
\hline & & & & & \\
\hline
\end{tabular}

Fuente: elaboración propia.

\section{ANÁLISIS}

Resulta notable reconocer que a los maniquís, aparentemente iguales en todos los países, se les implementan cambios que refuerzan el interés de los locales por mostrar el cuerpo "perfecto" que quieren que la gente vea. Es una manifestación clara de lo que Turner (2004) denominó el potencial del cuerpo para modelar el desarrollo sociocultural.

Teniendo en cuenta lo anterior, las diferencias esenciales se presentaron en los detalles de los maniquís hechos para estratos sociales bajos. Los más evidentes fueron las modificaciones corporales que les añaden en ciudades como Armenia (Colombia) y San Cristóbal (Venezuela), donde representaban mujeres con grandes prótesis mamarias (fotografía 1). Cabe anotar que esas dos ciudades, similares culturalmente, son centros de las operaciones estéticas a las que acuden mujeres y hombres de todo el mundo, por su bajo costo.

Según la Sociedad Internacional de Cirugía Estética (El Tiempo, 2018), Colombia es el cuarto país en el mundo en el que más se producen cirugías estéticas, y Venezuela está dentro de los veinte primeros (BBC News, 2018). En ambos países se aplica la liposucción y la implantación de prótesis mamarias, principalmente, lo que indica el fuerte culto al cuerpo y el fetichismo que hay hacia los pechos femeninos.

En Ciudad Juárez (México), los maniquís se comparan con los de sus vecinos de Estados Unidos, por lo que estos representan el gusto norteamericano, de mujeres delgadas con pocas curvas. En Perugia, Italia, por su parte, las modificaciones estaban en los maniquís de los almacenes exclusivos: se observa un énfasis en la expresión de las manos, cuidadosamente detalladas, con dedos largos y huesudos, dispuestos de manera artística.

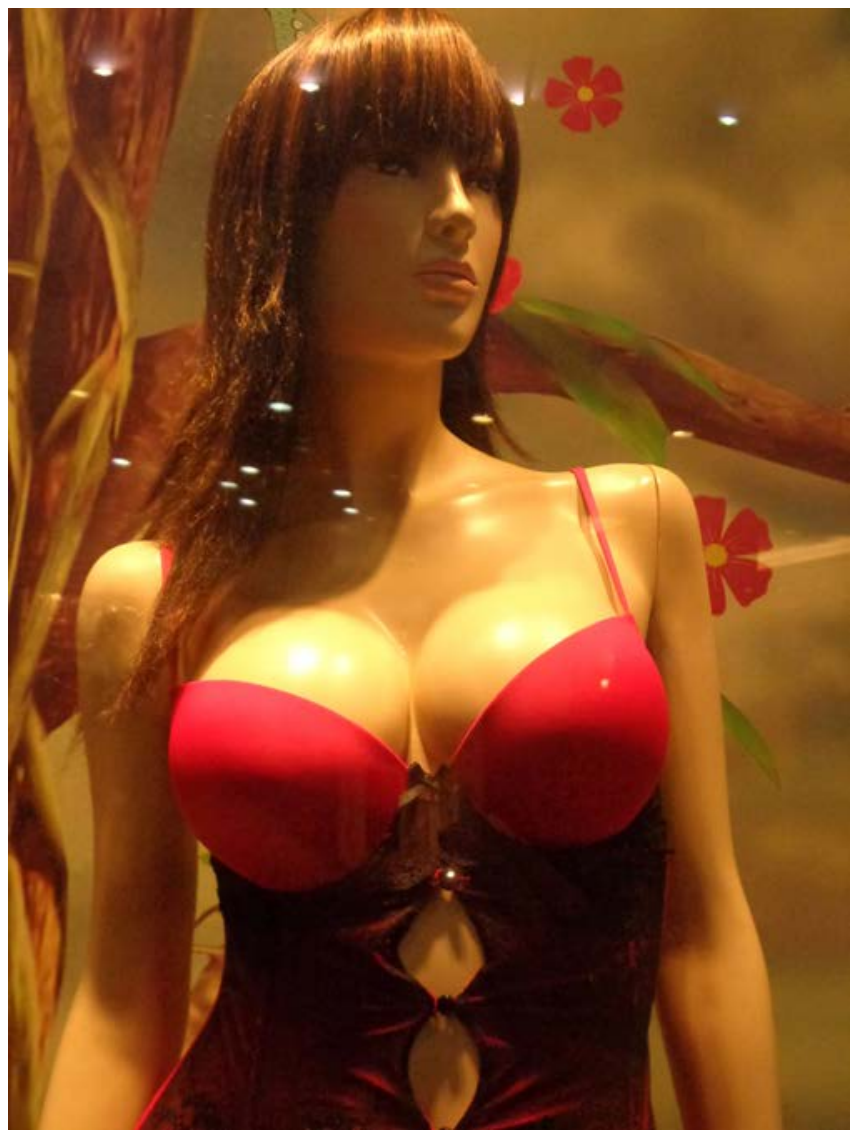

Fotografía 1. Maniquí que representa a una mujer con prótesis mamarias, propio de culturas en los que la modificación del cuerpo es común.

Fuente: Lilia Ines López 
Las manos son un recurso artístico reconocido: simbolizan la actividad humana, y sus gestos son narrativos (Cerrada, 2008). En la fotografía 2, aparece una mano perteneciente a un maniquí de la ciudad de Perugia; su gesto denota autocontrol y apertura hacia la mirada de otros.

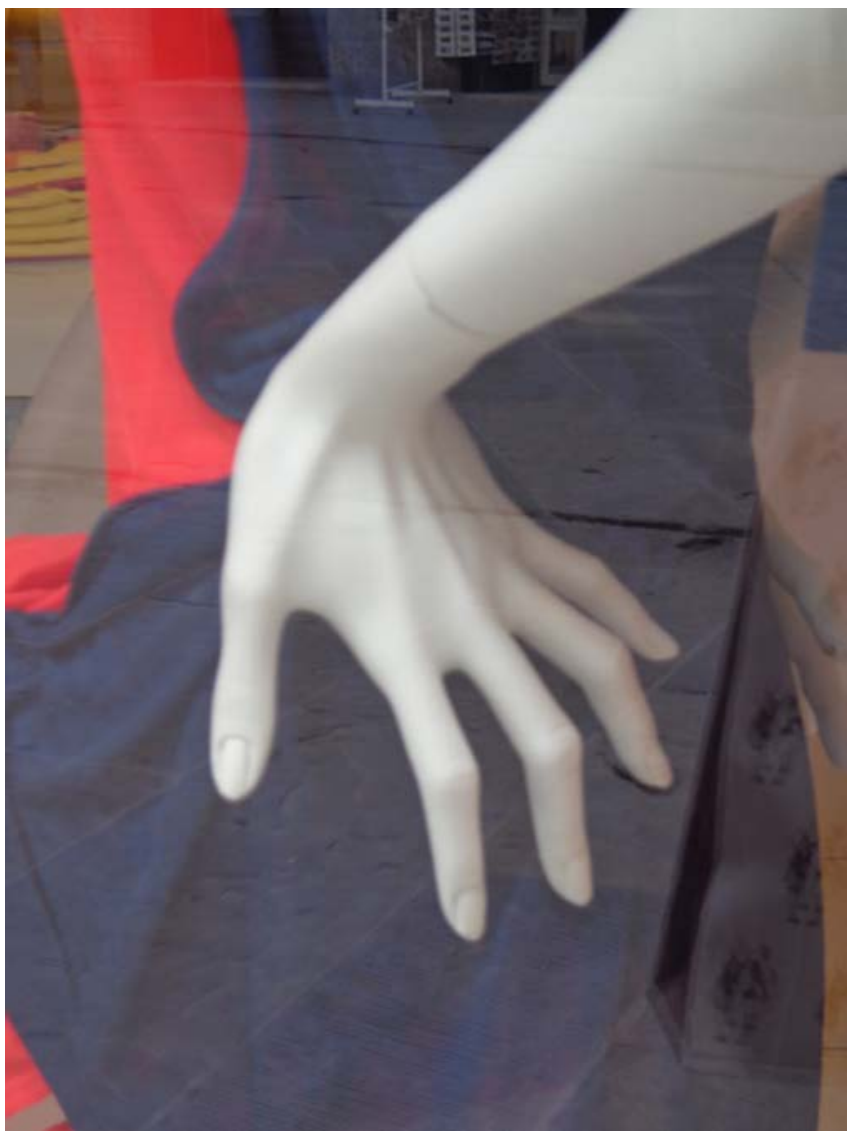

Fotografía 2. En Italia, prefieren darles detalles a las manos, que suelen ser largas y delgadas. Foto tomada en Perugia, Italia.

Fuente: Sandra Leal

Los sectores comerciales tienen como referente central las vitrinas de moda, adornadas con la exhibición de maniquís. Estos, al atraer y provocar el voyerismo, así como el deseo, se convierten en una imagen de lo nuevo-sagrado, como lo propuso Mircea Eliade (1981), lo cual no exige creencia, pero sí requiere fieles seguidores para mantener su existencia.

En un mundo centrado en lo comercial, la belleza promovida se homogeniza, se unifica en unas cuantas líneas, pero cuando aquel se empieza a hacer viejo, entra en contradicción. La vejez es fea y decadente, y el rechazo cultural del que esta goza llena de con- notaciones negativas a las personas mayores (Becerril, 2011). En este orden de ideas, el cuerpo viejo se excluye, mientras el joven se incluye; hay toda una batalla contra el proceso natural y biológico del envejecimiento, en nombre de la eterna juventud (véase fotografía 3). El cuerpo joven, exhibido en contraposición al cuerpo viejo, de inmediato remite a la idea, socialmente establecida, de que la apariencia en nuestro siglo es fundamental para la identidad.

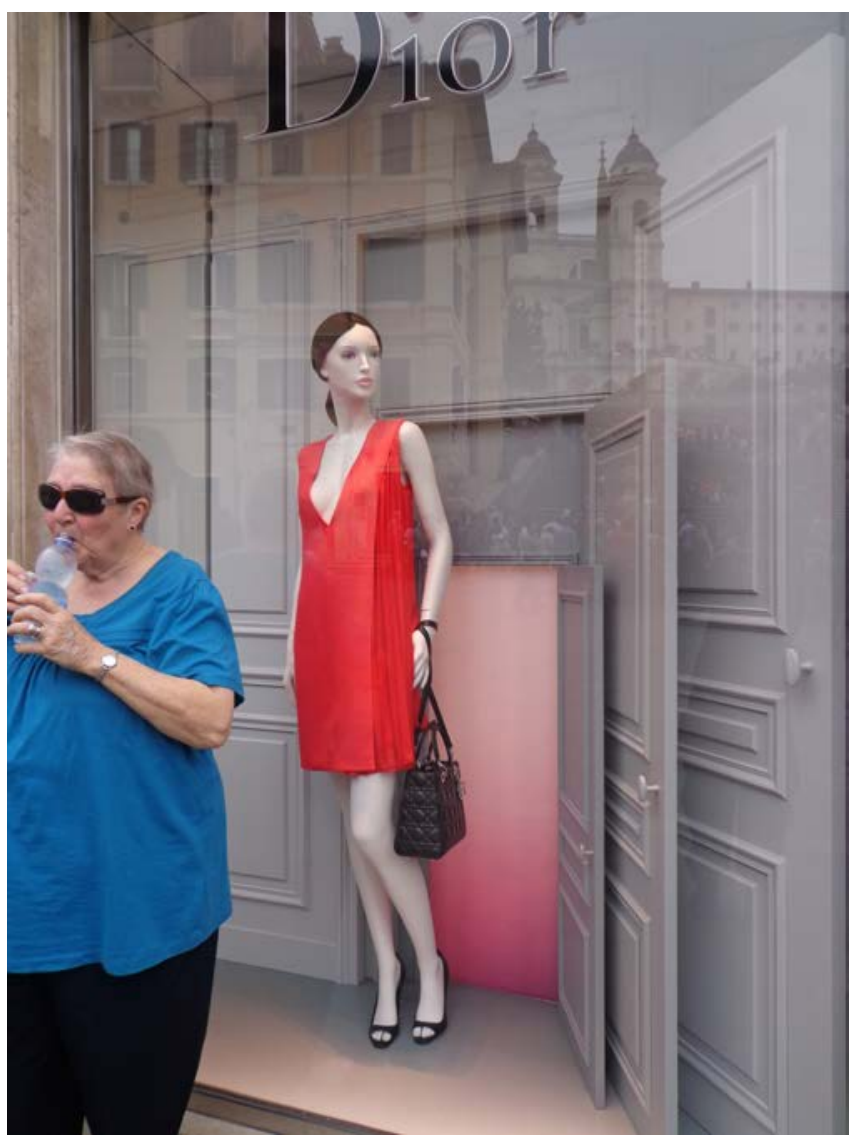

Fotografía 3. Las exigencias sociales sobre el aspecto corporal se hacen evidentes en las vitrinas. Foto tomada en Perugia, Italia.

Fuente: Sandra Leal

\section{El círculo de la vida según los fabricantes de la moda}

Analizamos los maniquís desde la perspectiva del cuerpo-lenguaje, es decir, como signos dispuestos a ser descritos como cuerpos en los que el movimiento y las poses expresan una gramática corporal. La mirada al frente; los brazos relajados a los lados, o las manos en la cintura; los hombros abiertos, dejando libre el pecho y el abdomen mostraron unas poses confiadas y seguras. La pose de los maniquís 
europeos (aunque estos, en su mayoría, son similares a las nuestros) suele manifestar una mayor afectación, elevando los brazos o colocándolos en posiciones inverosímiles. En algunos casos, presentan posturas desenfadadas.

Fotos tomadas en la ciudad de Armenia, Colombia y Perugia, Italia.

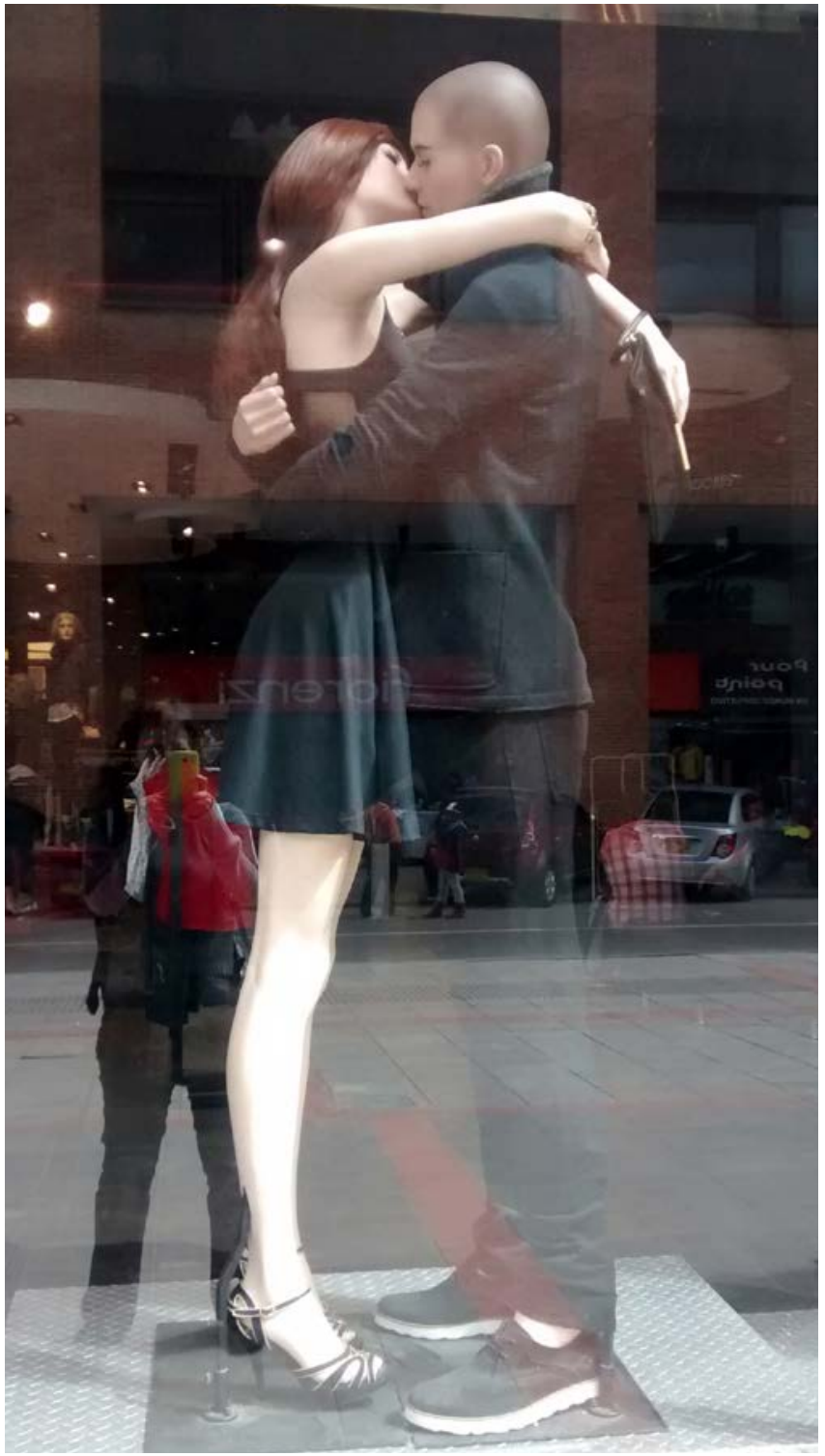

Fotografía 4. Los maniquís se enamoran

Fuente: Paola Rodríguez

Como cuerpo-objeto, en referencia a cómo la cultura representa el cuerpo, los maniquís manifiestan los estereotipos de belleza de delgadez y sensualidad que priman en Occidente. Los latinoamericanos se diferencian de los europeos en cuanto a la voluptuosidad de las figuras.

Bajo la categoría de cuerpo-referencia, se estudia el cuerpo como soporte de otros signos: tatuajes, peinados, accesorios o vestuario. En este punto, se destaca que a los maniquís masculinos se les agregan accesorios como gafas de marcos gruesos, mientras a los femeninos les ponen pestañas postizas. Una lectura de este hecho destaca algunos estereotipos de género, como la relación entre la masculinidad y la intelectualidad, y, por su parte, la importancia del aspecto en las mujeres.

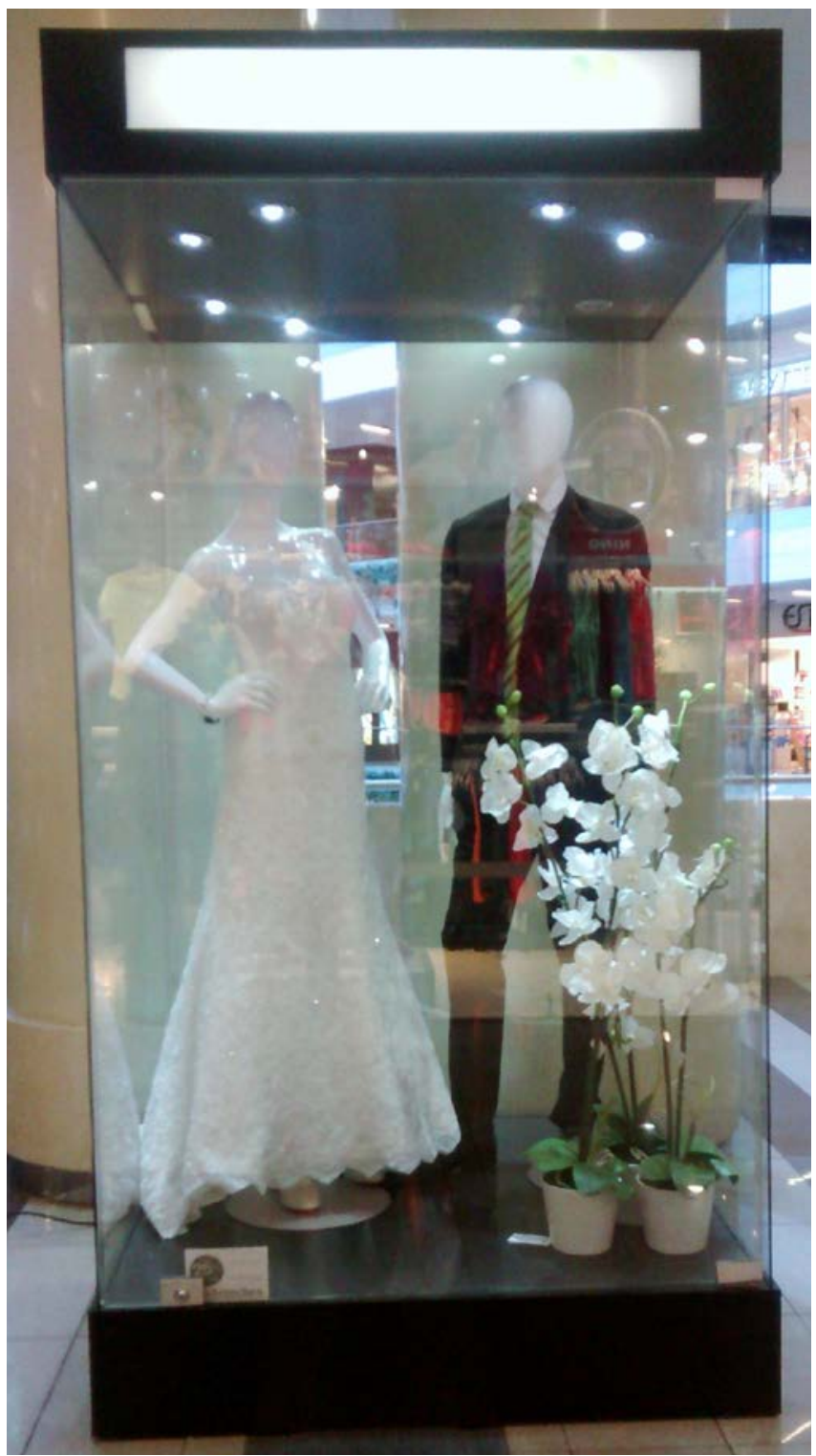

Fotografía 5. Los maniquís se casan

Fuente: Sandra Leal 

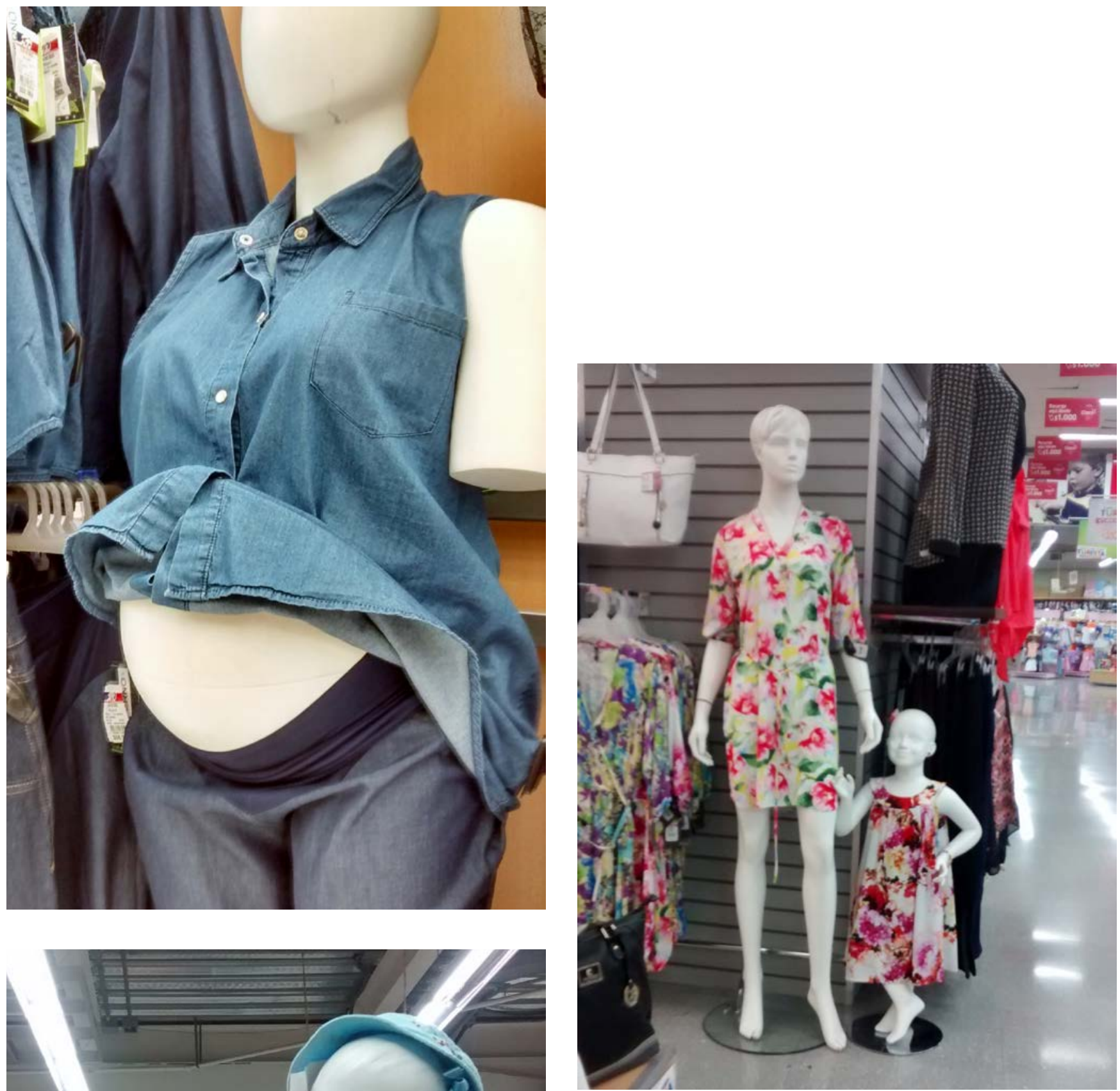

Fotografías 6, 7 y 8. Los maniquís tienen hijos Fuente: Paola Rodríguez 


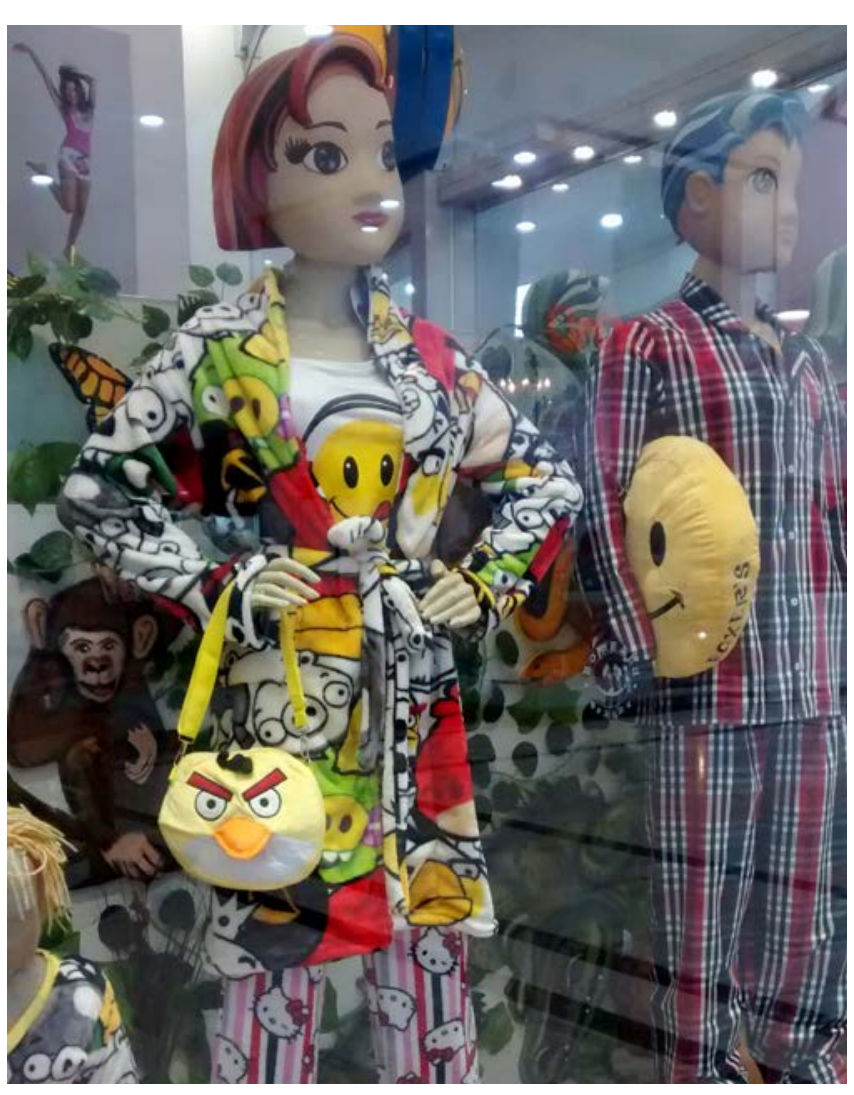

Fotografía 9. Los hijos crecen y llegan a la adolescencia ... Pero jamás llegan a viejos

Fuente: Lilia Ines López

En cuanto al cuerpo-espacio, los maniquís, como modelos que poseen un volumen, ocupan espacio y prestan un servicio de expresión estética, en representación de los seres humanos ocupan un espacio. Pero un espacio diferenciado, separado por el vidrio de las vitrinas, que genera una sensación de dentro y fuera. La organización de las vitrinas intenta generar un escenario semirrealista, con características de lo fantástico, para delimitar un espacio de ensoñación en los espectadores y permitirles visualizarse como seres perfectos.

\section{CONCLUSIONES}

Los sectores comerciales tienen como referente central las vitrinas de moda. Estas están adornadas con la exhibición de maniquís, que se han convertido en un nuevo-sagrado. Si bien no exigen creencia, sí requieren fieles seguidores para mantener su existencia. En este mismo sentido, el estigma social alrededor del cuerpo creado por los medios, y perpetuado por los maniquís, convierte a cada ser humano en su propio estigmatizador, por no cumplir con los estándares de un cuerpo bello.

El gran logro de la industria cultural centrada en el cuerpo es la de convertirnos, a cada uno de nosotros, en un perpetuador de esas creencias. El "cuerpo gordo" o el "cuerpo envejecido" son catalogados como abominaciones que despiertan pasiones tiránicas entre unos y otros, en un mundo que está abierto al libertinaje de la opinión.

Se encontró que en todas las ciudades, los lugares donde se ubican los almacenes de cadena se constituyen en nodos principales, donde los ciudadanos interactúan y son alentados al deseo.

Aunque los maniquís representan varias edades, desde bebés hasta adultos (véanse las fotografías 4-8), no representan a las personas de más de 30 años, y esto se evidencia en las posturas, así como en los rasgos de los muñecos.

La moda, a través de los maniquís, no se relaciona solo con las prendas; en sí misma, abarca la expresión de los individuos y de lo que estos pueden llegar a ser. Esto se hace a través de una buena interpretación de la filosofía de vida, que envuelve a las diferentes culturas, mostrada a través de un prototipo o un modelo estándar de un almacén que, a pesar de no ser, proyecta en el imaginario a un ser humano real.

\section{REFERENCIAS}

BвC News. (2018). Las extranjeras (y venezolanas) que aprovechan la crisis y viajan a Venezuela a realizarse operaciones estéticas a "bajo costo". https://www.bbc. com/mundo/noticias-america-latina-46617242

Bernal, J. (2014). Aproximación a la noción de mujer-objeto. Consideraciones entre las teorías feministas y la teoría del intercambio simbólico de Jean Baudrillard. http://repository.urosario.edu.co/ bitstream/handle/10336/8998/52982616-2014. pdf?sequence $=1$

Becerril, R. (2011). Cuerpo, cultura y envejecimiento. Análisis de la imagen corporal en la publicación 60 y más (Imserso). Ágora para la EF y el deporte. https://www5. uva.es/agora/revista/13_2/agora13_2a_becerril

Bourdieu, P. (1986). Notas provisionales sobre la percepción social del cuerpo. En Materiales de sociología crítica (pp. 183-194). Madrid: La Piqueta. 
Cedeño, M., Centeno, L. y D’aubeterre, L. (2015). La exhibición en vitrinas como estrategia de marketing visual. Un estudio transdisciplinario de mercadeo visual. s.l.: Editorial Académica Española.

Cerrada, M. (2008). La mano a través del arte: simbología y gesto de un lenguaje no verbal. [Tesis de doctorado, Universidad Complutense de Madrid]. Repositorio institucional UCM. https://eprints.ucm.es/7539/1/ T29915.pdf

Colle, R. (2011). El análisis de contenido de las comunicaciones. Tres ejemplos de aplicaciones. Tenerife: Sociedad Latina de Comunicación Social.

Eco, U. (1987). Lector in fabula. Barcelona: Lumen.

El Tiempo. (2018). Colombia, cuarto país donde más se practican cirugías plásticas. https://www.eltiempo. com/vida/salud/colombia-es-el-cuarto-pais-con-mascirugias-esteticas-en-el-mundo-288828

Eliade, M. (1981). Lo sagrado y lo profano. Madrid: Guadarrama/Punto Omega.

Finol, J. (1999). Semiótica del cuerpo: el mito de la belleza contemporánea. Opción, 15(28), 101-124.

Finol, J. (2008). Discurso, isotopía y neonarcisismo: contribución a una semiótica del cuerpo. TELOS. Estudios interdisciplinarios en Ciencias Sociales, 10(3), 383-402.

Goffman, E. (2006). Estigma, la identidad deteriorada. Buenos Aires: Amorrortu.

Horkheimer, M. y Mattelart, A. (1988). La industria cultural. Iluminismo como mistificación de masas. Buenos Aires: Suramericana.
Infantino, J. (2010). Prácticas, representaciones y discursos de corporalidad. La ambigüedad de los cuerpos circenses. Runa, 31. http://revistascientificas.filo.uba. ar/index.php/runa/article/view/757/734

Jameson, F. (1991). El posmodernismo o la lógica cultural del posmodernismo avanzado. Barcelona: Paidós.

Le Breton, A. (2002). La sociología del cuerpo. http://www. bioenergeticalatam.com.ar/docus/LeBreton.pdf

Mattelart, A. y Piemme, J. (1982). Las industrias culturales: el futuro de la cultura en juego. México: Fondo de Cultura Económica.

Mernissi, F. (2006). El harén en Occidente. Barcelona: Espasa.

Planella, J. (2005). Pedagogía y hermeneútica del cuerpo simbólico. Revista de Educación, 336, 189-201. http:// femrecerca.cat/jordi_planella/files/re336_11-1.pdf

Silva, A. (2006). Imaginarios urbanos. Bogotá: Tercer Mundo.

Szpilbarg, D. y Saferstein, E. (2014). De la industria cultural a las industrias creativas: un análisis de la transformación del término y sus usos contemporáneos. https:// dialnet.unirioja.es/servlet/articulo? codigo $=5718866$

Turner, B. (2004). Los avances recientes en la teoría del cuerpo. Revista Reis, 68(94), 11-39. http://ih-vm-cisreis.c.mad.interhost.com/REIS/PDF/REIS_068_04.pdf

Uro, M. (2006). Capital simbólico e investigación: una nota sobre el capital corporal. Revista Educación Física y Ciencia, 8. https://www.efyc.fahce.unlp.edu.ar/article/ view/EFyCv08a03/5659 